\title{
Segregation and Pathfinding of Callosal Axons through EphA3 Signaling
}

\author{
Mitsuaki Nishikimi, Koji Oishi, Hidenori Tabata, Kenichi Torii, and Kazunori Nakajima \\ Department of Anatomy, Keio University School of Medicine, Tokyo 160-8582, Japan
}

The corpus callosum, composed of callosal axons, is the largest structure among commissural connections in eutherian animals. Axon pathfinding of callosal neurons has been shown to be guided by intermediate targets, such as midline glial structures. However, it has not yet been understood completely how axon-axon interactions, another major mechanism for axon pathfinding, are involved in the pathfinding of callosal neurons. Here, we show that callosal axons from the medial and lateral regions of the mouse cerebral cortex pass through the dorsal and ventral parts, respectively, of the corpus callosum. Using an explant culture system, we observed that the axons from the medial and lateral cortices were segregated from each other in vitro, and that this segregation was attenuated by inhibition of EphA3 signaling. We also found that knockdown of EphA3, which is preferentially expressed in the lateral cortex, resulted in disorganized segregation of the callosal axons and disrupted axon pathfinding in vivo. These results together suggest the role of axonal segregation in the corpus callosum, mediated at least in part by EphA3, in correct pathfinding of callosal neurons.

\section{Introduction}

Commissural axons running through the corpus callosum (CC) transfer information between the right/left hemispheres, comprising a complex neural network in eutherian animals (Mitchell and Macklis, 2005; Mihrshahi, 2006). The CC, composed of callosal neuronal axons, is the largest commissural-axons structure in the brain. One of the most important features of these axons is that they have homotopic interhemispheric connections, whereby the axons from the medial and lateral regions project to the contralateral medial and lateral regions, respectively (Mizuno et al., 2010).

Mechanisms involved in axon pathfinding can be divided mainly into two categories. One is utilization of intermediate targets, by which axons are guided through attractive and repulsive interactions (Plachez and Richards, 2005; Lindwall et al., 2007). The other is utilization of axon-axon interactions, such as the interactions between the pioneer axons and the following axons observed in several systems (Plachez and Richards, 2005).

Received June 29, 2011; revised Sept. 5, 2011; accepted Sept. 19, 2011.

Author contributions: M.N., K.O., and K.N. designed research; M.N., K.O., H.T., and K.T. performed research; M.N., K.O., H.T., and K.T. contributed unpublished reagents/analytic tools; M.N., K.O., and K.N. analyzed data; M.N., K.O., and K.N. wrote the paper.

This work was supported by the Strategic Research Program for Brain Sciences ("Understanding of molecular and environmental bases for brain health"), Grant-in-Aid for Scientific Research, and Global COE Program of the Ministry of Education, Culture, Sports, Science and Technology of Japan, the Japan Society for the Promotion of Science, and the Promotion and Mutual Aid Corporation for Private Schools of Japan. We thank Dr. Masaru Okabe, Dr. Tatsumi Hirata, Dr. Jun-ichi Miyazaki, Dr. David A. Feldheim, Dr. Takuro Maruyama (Research Institute of Environmental Medicine, Nagoya University), Dr. Nobuhiko Yamamoto (Graduate School of Frontier Biosciences, Osaka University), and Dr. Masayuki Masu (Institute of Basic Medical Sciences, University of Tsukuba) for reagents and advice, as well as members of the Nakajima laboratory for their helpful discussions and technical assistance.

The authors declare no competing financial interests.

Correspondence should be addressed to either of the following: Kazunori Nakajima or Koji Oishi, Department of Anatomy, Keio University School of Medicine, 35 Shinanomachi, Shinjuku-ku, Tokyo 160-8582, Japan. E-mail: kazunori@z6.keio.jp or k-oishi@sc.itc.keio.ac.jp.

DOI:10.1523/JNEUROSCI.3303-11.2011

Copyright $\odot 2011$ the authors $\quad 0270-6474 / 11 / 3116251-10 \$ 15.00 / 0$
Many studies have revealed that interactions between callosal axons and intermediate targets, including the midline glial structures (e.g., indusium griseum) (Shu and Richards, 2001; Mendes et al., 2006; Tole et al., 2006; Piper et al., 2009) and the neurons in the CC (Niquille et al., 2009), are essential for callosal-axon pathfinding. However, although increasing evidence has revealed the importance of axon-axon interactions in other systems, such as retinal, spinal and olfactory neurons (Chan and Chung, 1999; Plas et al., 2005; Gallarda et al., 2008; Imai et al., 2009), it still remains unclear whether this mechanism plays an important role in callosal axon pathfinding.

The Eph family of receptor tyrosine kinases and their membrane-anchored ephrin ligands are key regulators of axon guidance (Kaprielian et al., 2001). Eph receptors are divided into two subclasses, $\mathrm{A}$ and $\mathrm{B}$, according to the sequence homology and binding affinity for their ligands, ephrins A and B, respectively (Martínez and Soriano, 2005; Bush and Soriano, 2009). The EphB receptors have been well studied in callosal axon pathfinding and shown to have important roles, especially in the interactions with the midline glial cells (Mendes et al., 2006; Bush and Soriano, 2009). On the other hand, only a few studies have explored the role of EphA receptors during CC development (Hu et al., 2003), despite the EphA receptors being known to function as a key player in axonal development in other systems (Kaneko and Nighorn, 2003; Lemke and Reber, 2005). We previously reported the dynamic expression profiles of EphA3 in the developing brain, including the CC (Kudo et al., 2005), which raised the possibility that EphA3 signaling might play a role in callosal axon guidance.

In the present study, we show that the callosal axons from the medial and lateral cortices project through the different portions of the CC. We found that the medial and lateral cortical axons were segregated from each other in an in vitro culture and that this effect was mediated, at least in part, by EphA3. Consistently, EphA3 knockdown resulted in disorganized segregation of the 
callosal axons and disrupted axon pathfinding at the point where the growing callosal axons changed direction.

\section{Materials and Methods}

Mouse strains. All the animal experiments were performed according to the Guidelines for the Care and Use of Laboratory Animals of Keio University School of Medicine. Pregnant ICR mice were purchased from Japan SLC Transgenic C57BL/6-Tg (CAG-EGFP) C14-Y01-FM131Osb mice expressing the green fluorescent protein (GFP) ("GFP mice") (Ikawa et al., 1998) were obtained from Dr. Masaru Okabe (Genome Information Research Center, Osaka University) and maintained at our animal facilities. We analyzed their embryos of either sex. The noon of the day on which a vaginal plug was detected was designated as embryonic day 0.5 (E0.5).

Visualization of the axons from the medial and lateral cortices by fluorescent lipophilic tracers. 3,3'-Dioctadecyloxacarbocyanine perchlorate (DiO, Invitrogen) and 1, 1' -dioctadecyl-3,3,3',3'tetramethylindocarbocyanine perchlorate (DiI, Invitrogen) crystals were used to visualize the pathways of the commissural axons originating from the medial and lateral cortices, respectively. Mouse brains at postnatal day 0.5 (P0.5) were perfused with $4 \%$ paraformaldehyde (PFA) in $0.1 \mathrm{M}$ phosphate buffer (PB). The crystals were directly injected into the medial and lateral cortices. After the injection, the brains were incubated in $2 \% \mathrm{PFA} / \mathrm{PB}$ at $37^{\circ} \mathrm{C}$ in a dark environment. After 3 weeks of incubation, the brains were sliced into $200 \mu \mathrm{m}$ coronal sections with a vibratome.

Explant culture of the medial and lateral cortices. Brains were removed from E16.5 ICR and GFP-heterozygous mice, embedded in 3\% lowmelting-point agarose, and sliced coronally into $200 \mu \mathrm{m}$ sections with a vibratome. Then, the medial and lateral cortical explants were dissected from the slices, as shown in Figure $2 \mathrm{~A}$ (see below), placed at a distance of $150-300 \mu \mathrm{m}$ on coverslips coated with poly-D-lysine (PDL, $100 \mu \mathrm{g} /$ $\mathrm{ml}$, Sigma) and laminin from Engelbreth-HolmSwarm murine sarcoma cells ( $50 \mu \mathrm{g} / \mathrm{ml}$, Sigma), and cultured in Neurobasal medium (Invitrogen) supplemented with B27 (Invitrogen). After 4 dincubation in vitro, the sections were fixed and stained for class III $\beta$-tubulin (TuJ1, 1:1000, Covance) or L1CAM (1:100, Millipore Bioscience Research Reagents), and GFP (1:1000, MBL International) to enhance GFP fluorescence.

In the Fc experiments, which were performed in the same manner as described above except that E16.5 ICR mice and homozygous mice for GFP were used, $30 \mu \mathrm{g} / \mathrm{ml}$ EphA3-Fc (R\&D Systems) or IgG-Fc (Jackson Laboratory) was added into the culture medium after 1 and $2 \mathrm{~d}$. After an additional $3 \mathrm{~d}$, the explants were fixed and stained for L1CAM or class III $\beta$-tubulin (TuJ1) to visualize neurites as described above. L1CAM and TuJ1 staining yielded essentially same results. The judgment as to whether the axons were mingled or separated was made in a blinded manner.

In situ hybridization. P0.5 mice were perfused with $4 \%$ PFA in PB. The brains were removed and immersed in the same fixative at $4^{\circ} \mathrm{C}$ for $16 \mathrm{~h}$. The brains were cryoprotected by immersion in $20 \%(\mathrm{w} / \mathrm{v})$ sucrose/PBS, $500 \mu \mathrm{m} ; C, G, 0,100 \mu \mathrm{m}$.
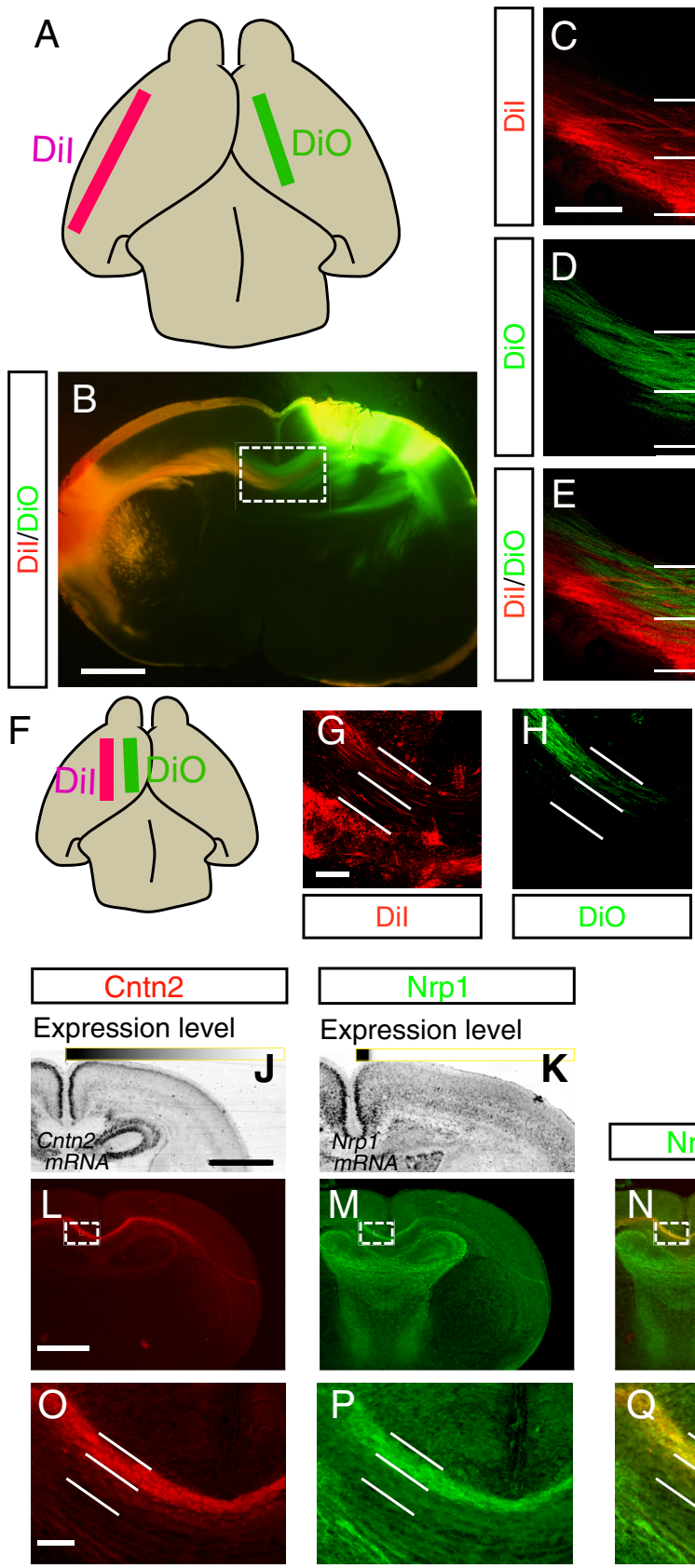
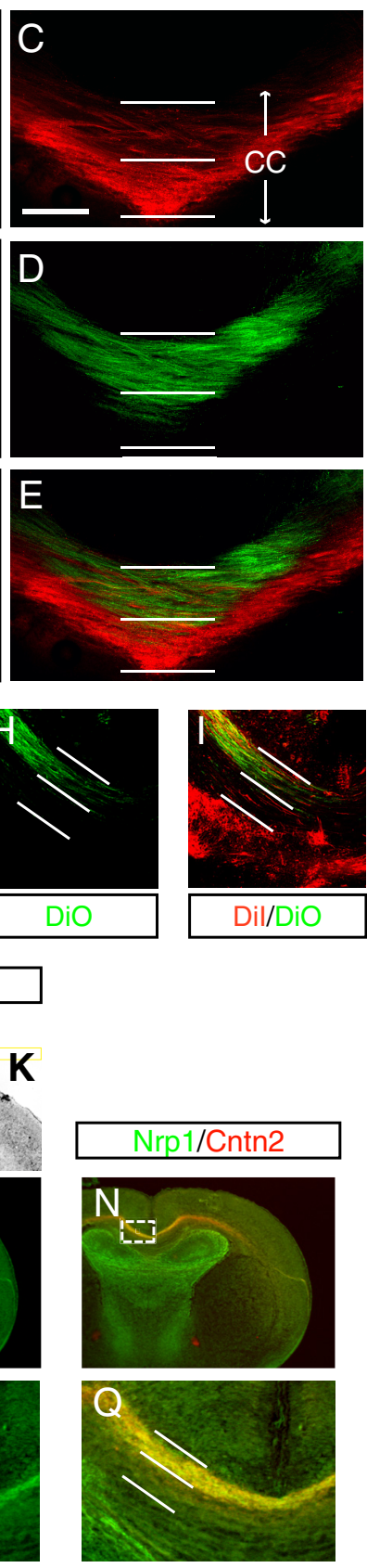

Figure 1. Dil and Di0 labeling of the medial and lateral cortices and the expression patterns of Cntn2 and Nrp1.A, Injection sites of Dil and Di0 crystals. Dil and DiO were injected into the lateral and medial cortices, respectively. $\boldsymbol{B}$, The labeled axons in a coronal section are shown at low magnification. $\boldsymbol{C}-\boldsymbol{E}$, The axons in the white box in $\boldsymbol{B}$ are shown at high magnification. The lateral cortical axons are segregated from the medial cortical axons in the CC. $F$, Injection sites of Dil and Di0 crystals. Di0 and Dil were injected into the medial-most (retrosplenial) cortex and a more lateral part of the medial cortex, respectively. $\mathbf{G}-\mathbf{I}$, The labeled axons in the CC are shown at high magnification. Both the axons of the retrosplenial cortex and the "more lateral" medial cortex passed through the dorsal part of the CC. J, $\boldsymbol{K}$, In situ hybridization for Cntn2 and Nrp1. Yellow rectangles show the gradients of expression. $\mathbf{L}-\mathbf{Q}$, Immunohistochemistry for $(n t n 2$ and Nrp1. The boxed regions in $\boldsymbol{L}-\boldsymbol{N}$ are shown at high magnification ( $\mathbf{O}-\mathbf{Q})$. Scale bars: $\boldsymbol{B}, \boldsymbol{J}, \boldsymbol{L}$,

and embedded in Tissue-Tek OCT compound (Sakura Finetek USA). Serial coronal sections were prepared with a cryostat (CM1900, Leica) at a thickness of $16 \mu \mathrm{m}$ and dried at $42^{\circ} \mathrm{C}$ for $2 \mathrm{~h}$.

For synthesizing RNA probes, FANTOM cDNA clones were used as the PCR template (Kawai et al., 2001; Okazaki et al., 2002). DNA templates were amplified by PCR using an M13 primer pair and purified using the Wizard SV Gel and a PCR Clean-Up system (Promega). Digoxigenin (DIG)-labeled RNAs were synthesized using the DIG RNA labeling kit (Roche) by incubating the purified PCR prod- 
ucts with SP6 or T7 RNA polymerase for $2 \mathrm{~h}$ at $37^{\circ} \mathrm{C}$. In situ hybridization was performed as described previously (Tachikawa et al., 2008).

Immunohistochemistry. The sections were blocked with PBS containing 2\% normal donkey serum (Millipore Bioscience Research Reagents) and $0.5 \%$ Triton X-100 at room temperature for $1 \mathrm{~h}$, and then incubated with the primary antibodies overnight at $4^{\circ} \mathrm{C}$. They were washed with PBS-Triton X-100 and incubated with FITC- or TRITC-labeled secondary antibodies (Jackson Laboratory). The primary antibodies used were as follows: rabbit anti-EphA3 (sc-919, 1:250, Santa Cruz Biotechnology), mouse anti-Cntn2 (TAG-1; 1:10, culture supernatant, Developmental Studies Hybridoma Bank), and rabbit anti-Nrp1 (1:250, kind gift from Dr. Tatsumi Hirata, Division of Brain Function, National Institute of Genetics).

Primary dissociated culture of the medial and lateral cortices. Fc-fusion proteins (ephrin-A5-Fc, R\&D Systems; or IgG-Fc, $300 \mathrm{~nm}$, each) were preclustered with a 1:3 molar ratio of an anti-human IgG Fc antibody (ICN Pharmaceuticals) for $\sim 3 \mathrm{~h}$ on ice. Culture dishes were then coated with the Fc protein solutions overnight at $4^{\circ} \mathrm{C}$. The medial and lateral cortices were removed in the same manner as the explant culture experiments described above, dissociated with $0.1 \%$ trypsin, and plated on the coated dish. After $6 \mathrm{~h}$ of incubation, we further added the Fc-fusion proteins to the dishes. The cortical cells were cultured for additional $2 \mathrm{~d}$, fixed, and stained for class III $\beta$-tubulin (TuJ1). We examined axonal growth by measuring the length of the primary neurite, the longest neurite of each cell, using the NeuronJ software (ImageJ, NeuronJ plugin, $\mathrm{NIH}$.

Immunoblotting. 293T cells were transfected with an EphA3 expression vector (CAGGS-EphA3) together with short-hairpin RNA (shRNA) expression vectors targeting EphA3 or control shRNA (Consh), using GeneJuice transfection reagent (Novagen). The pSilencer 3.0-H1 plasmid (Ambion) containing the H1 RNA promoter was used for construction of the shRNA vectors targeting EphA3 (EphA3sh\#1-\#4). The inserted sequence was $5^{\prime}$-TATGTGGATCAACATAGGTCCttgatatccgg gACCTATGTTGATCCACATA-3' (the lower-case letters indicate the linker sequence) for EphA3sh\#2 (the other sequences available upon request). Consh was purchased from Ambion. After $2 \mathrm{~d}$ culture, samples of whole-cell lysates were subjected to SDS-PAGE and transferred to PVDF membranes for immunoblotting. The membranes were incubated in blocking buffer [5\% skim milk in Tris-buffered saline (TBS)] for $1 \mathrm{~h}$ at room temperature, followed by incubation with anti-EphA3 (1:250) in $3 \%$ bovine serum albumin/TBS overnight at $4^{\circ} \mathrm{C}$. After two washes with $0.05 \%$ Tween 20 in TBS, the membranes were incubated with HRP-labeled secondary antibody (DAKO) in blocking buffer for 40 min at room temperature. After two washes again with TBS, they were washed with $0.05 \%$ Tween 20 in TBS for 15 min. Finally, immunoreactive proteins were detected with ECL chemiluminescence reagents (GE Healthcare).

As for EphA5 knockdown, the pSilencer 3.0-H1 plasmid (Ambion) was used for the construction of the shRNA vectors targeting EphA5 (EphA5sh). The inserted sequence was 5'-GCAGCGCAGAGATTTCCT GttcaagagaCAGGAAATCTCTGCGCTGC-3'. To examine the efficiency of the EphA5sh vector, 293T cells were transfected with the HA-tagged intracellular domain of the EphA5 expression vector (CAGGS-EphA5; the original clone was a kind gift from Dr. David A. Feldheim, Department of Molecular, Cellular and Developmental Biology, University of California Santa Cruz, Santa Cruz, CA) and GFP, together with EphA5sh or Consh. After $1 \mathrm{~d}$ in culture, immunostaining for HA (1:1000, Covance) was performed to examine the expression level of EphA5.

In utero electroporation. In utero electroporation was performed under anesthesia with sodium pentobarbital, as described previously (Tabata and Nakajima, 2001). In brief, shRNA expression vectors $(4 \mathrm{mg} / \mathrm{ml})$ together with the pCAGGS vector (kind gift from Dr. Jun-ichi Miyazaki, Osaka University) carrying the enhanced GFP cDNA or the mCherry cDNA (CAGGS-EGFP or CAGGS-mCherry, $1 \mathrm{mg} / \mathrm{ml}$ ) were injected into the lateral ventricle of intrauterine E12.5 embryos, and electronic pulses $(31 \mathrm{~V}, 50 \mathrm{~ms}, 4$ times) were then applied using an electroporator (CUY21, Nepa Gene) equipped with a forceps-type electrode (CUY650P3, Nepa Gene). In the rescue experiments, the EphA3sh\#2 and RNAi-
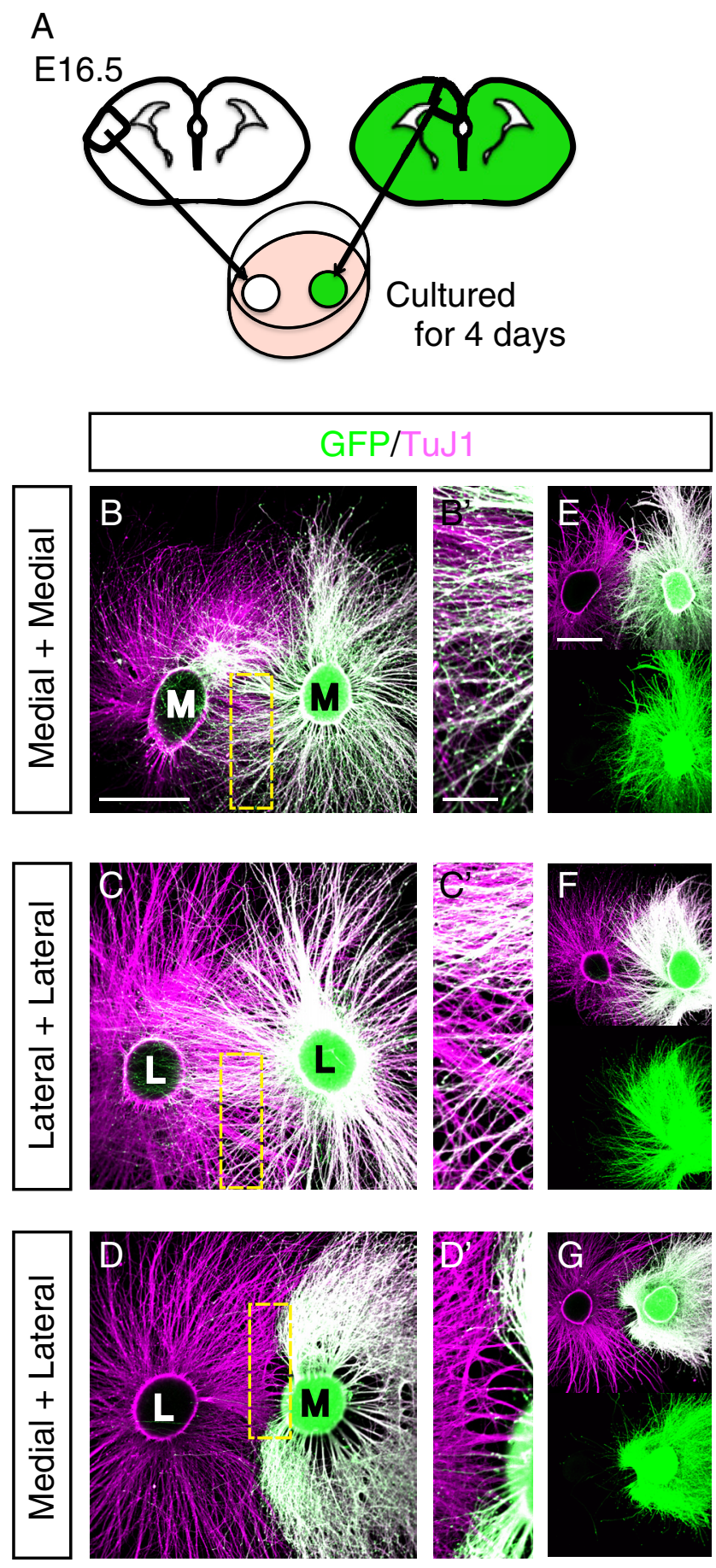

Figure 2. Interactions between axons originating from the medial $(\mathrm{M})$ and lateral $(\mathrm{L})$ cortical explants. $\boldsymbol{A}$, Outline of the dissection method used in this experiment. $\boldsymbol{B}-\boldsymbol{D}$, The axons of the medial and lateral cortical explants were visualized by anti-GFP (green) and Tuj1 immunostaining (magenta). $\boldsymbol{B}^{\prime}-\boldsymbol{D}^{\prime}$, High magnification of the boxed regions in $\boldsymbol{B}-\boldsymbol{D}$. $\boldsymbol{E}-\boldsymbol{G}, 0$ ther samples, which were processed in the same manner as described above. $\boldsymbol{B} / \boldsymbol{E}, \boldsymbol{C} / \boldsymbol{F}$, and $\boldsymbol{D} / \boldsymbol{G}$ are cocultures of the medial and medial cortices, lateral and lateral cortices, and medial and lateral cortices, respectively. The medial and lateral cortical axons tended to be separated from each other, while the axons from homotypic explants were well mixed, suggesting the repulsive effect between the axons from medial and lateral cortical explants. Scale bars: $\boldsymbol{B}, \boldsymbol{E}, 100 \mu \mathrm{m} ; \boldsymbol{B}^{\prime}, 25 \mu \mathrm{m}$.

resistant EphA3-expressing vector (resEphA3) (2 mg/ml each), carrying three point mutations in the sequence which the EphA3-silencing vector targeted, or EphA3sh\#2 and empty pCAGGS vector ( $2 \mathrm{mg} / \mathrm{ml}$ each) were introduced simultaneously with the CAGGS-EGFP plasmid. After $7 \mathrm{~d}$, 
the brains were fixed and sectioned as described above. Cryosections were immunostained with a rabbit anti-GFP antibody (1: 1000, zcomMBL International). Fluorescent images were obtained with a confocal laser microscope FV300 or FV1000 (Olympus). We measured the intensity of the GFP signals of the callosal axons in a $70 \mu \mathrm{m} \times 210 \mu \mathrm{m}$ rectangle on both the ipsilateral (before entering the CC) and contralateral (after leaving the CC) sides at the positions indicated in Figure $7 G$ (see below). We then calculated the ratio of the axonal GFP signals on the corresponding contralateral sides using the Adobe Photoshop software. In the coculture experiments illustrated in Figure 5 (see below), the mCherry fluorescence signal was enhanced by immunostaining with a rabbit antibody against DsRed (1:300, Clontech). To quantify the invasion rates of the lateral cortical axons into the medial cortical axons, we calculated the ratio of the intensity of mCherry-positive axons over the border between the medial and lateral cortical axons to the total intensity of mCherry-positive lateral cortical axons, as shown in Figure $5 F$ (see below).

\section{Results}

Dorsoventral arrangement of the callosal axons originating from the medial and lateral cortices in the $\mathrm{CC}$

The CC is composed of a huge number of callosal axons. Although this large structure is well arranged rostrocaudally such that axons from the rostral and caudal regions of the cerebral cortex project through the rostral and caudal portions of the CC, respectively (Matsunami et al., 1994), the mediolateral arrangement of the callosal axons is less clear. To investigate the arrangement of the axons from the medial and lateral cortices in the CC, we labeled them by injecting the lipophilic tracers DiO and DiI, respectively (Fig. $1 A$ ). We found that the axons from the medial cortex (roughly corresponding to the cingulate, motor and medial part of the primary somatosensory cortices) passed through the dorsal part of the CC, while those from the lateral cortex (roughly corresponding to the area around the secondary somatosensory cortex) passed through the ventral part, consistent with a recent report (Niquille et al., 2009) (Fig. $1 B-E$ ). The dorsal part of the CC, however, was previously shown to be the route for the axons from the retrosplenial cortex, which is located in the most medial region of the cerebral cortex (Matsunami et al., 1994). We therefore examined the axonal trajectories from the medial-most cortex (corresponding to the retrosplenial cortex) and a more lateral region of the medial cortex (Fig. 1F), and found that axons from both passed through the dorsal part of the $\mathrm{CC}$ in an overlapping manner (Fig. $1 G-I$ ). Moreover, we examined the mRNA and protein expressions of two molecular markers in the medial cortex. The expressions of Neuropilin1 (Nrp1) and Contactin2 (Cntn2) mRNA were medially restricted and relatively broad, respectively (Fig. $1 \mathrm{~J}, K$ ). However, their protein expressions in the axons revealed that the Cntn2-positive region and Nrp1-positive region in the CC were almost identical (Fig. $1 L-Q)$, further lending support to the idea that the callosal axons from the medial-most and less medial regions of the cortex become mixed. These results suggest that the axons in the CC can be divided into at least two major parts along the dorsoventral axis (dorsal half and ventral half), and that the axons do not align continuously reflecting the mediolateral topography of the cerebral cortex.

\section{Segregation of the axons from the medial and lateral cortical explants}

Given that the trajectories of the callosal neurons are not mingled but separated into two parts in the CC, we hypothesized the existence of active segregation mechanisms between the callosal axons originating from distinct cortical regions. To address this hypothesis, we examined the interactions between the axons originating from the same and different regions using an in vitro culture system. Explants of the medial and lateral cortices were cultured for $4 \mathrm{~d}$ at a distance of 150-300 $\mu \mathrm{m}$ in homotypic and heterotypic combinations, and the axons at the interface between the explants were analyzed (Fig. 2A). We first found that the axons from the homotypic explants (medial and medial, or lateral and lateral) mingled well with each other (Fig. $2 B, C, E, F)$. In contrast, the axons between the medial and lateral explants were separated from each other, with a sharp border between the axons (Fig. 2D,G). These data suggest a repulsive effect between the 


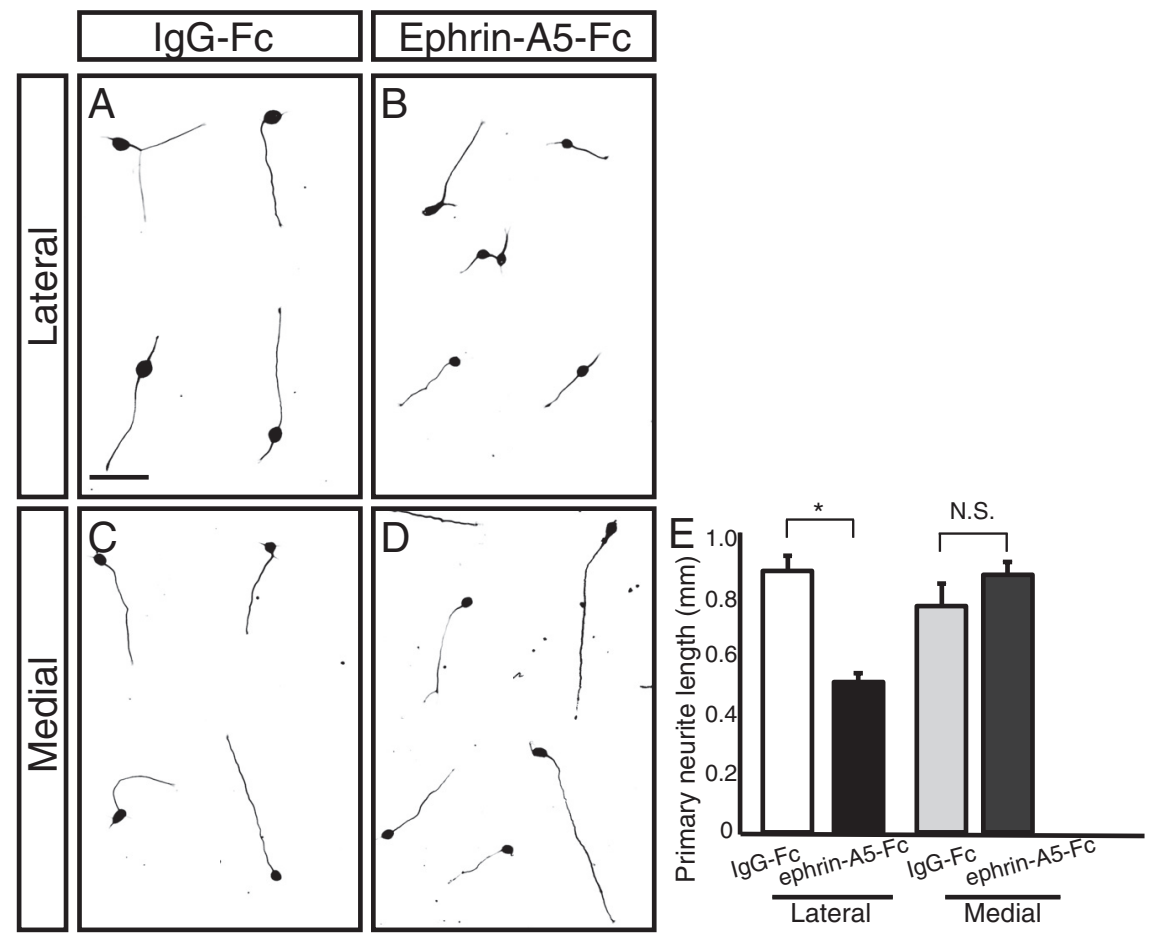

Figure 4. Ephrin-A5-Fc inhibits axonal growth of the lateral cortical neurons selectively. $A-D$, Primary dissociated culture of the lateral $(\boldsymbol{A}, \boldsymbol{B})$ or medial $(\boldsymbol{C}, \boldsymbol{D})$ cortices with the treatment of lgG-Fc or ephrin-A5-Fc. Ephrin-A5-Fc inhibited axonal growth of the lateral cortical neurons, while this inhibitory effect was not observed for the medial cortical neurons. $\boldsymbol{E}$, Quantitative data of the effect of ephrin-A5-Fc on the medial and lateral cortical neurons. ${ }^{*} p<0.05$. N.S., no significance. Scale bar: $A, 50 \mu \mathrm{m}$.

focused on the expression of EphA3 in the axons in this study. The results revealed that EphA3 protein was expressed in the ventral half of the CC (Fig. $3 F, H$ ). Importantly, the protein expression patterns of EphA3 and Cntn2 were mutually exclusive in the CC (Fig. $3 F-K$ ), further supporting the notion that the medial and lateral cortical axons are segregated into the dorsal and ventral parts of the CC, respectively (Fig. $1 B-E$ ).

\section{Inhibitory effect of ephrin-A5 on axonal growth of the lateral cortical neurons}

Given the repulsive effect between the medial and lateral cortical axons in vitro and the differential expression patterns of EphA3 and ephrin-A5, we hypothesized that EphA3 and ephrin-A5, mediators of repulsive signals (Egea and Klein, 2007), might be involved in this event through cell-cell interactions.

We first examined whether ephrin-A5 can act as a potent inhibitor for axonal growth of the lateral cortical neurons in vitro. We tested the effect of a soluble ephrin-A5, which contains the extracellular domain fused to the IgG Fc domain (ephrin-A5-Fc) and can activate EphA re-

axons from the medial and lateral explants, which may be the basis for the segregation of the callosal axons in vivo. Importantly, the medial and lateral cortical axons did not elongate toward the opposite directions, creating a border between the axons, suggesting that this repulsive action is mediated by direct axon-axon interactions or short-range diffusible factors (Gallarda et al., 2008).

\section{mRNA and protein expression patterns of EphA3 in the cerebral cortex of newborn mice}

To uncover the molecular mechanisms underlying this segregation, we focused on the differentially expressed genes along the mediolateral axis. We previously reported the expression profiles of EphA3 mRNA in the developing brain (Kudo et al., 2005) and confirmed again in this study that EphA3 mRNA was expressed more strongly in the lateral than in the medial part of the cerebral cortex on P0.5 (Fig. $3 B, D$ ). In contrast, the expressions of other EphA receptors were previously reported to be rather uniform or more spatially restricted in the cerebral cortex, suggesting a unique function of EphA3 (EphA4-6, Yun et al., 2003; EphA7, Miller et al., 2006). Interestingly, ephrin-A5, a high-affinity ligand for EphA3 (Himanen et al., 2004) was expressed more strongly in the medial cortex (Dufour et al., 2003) (Fig. 3C,E) at the rostrocaudal levels we analyzed. Importantly, EphA3 and ephrin- $A 5$ are expressed in the presumptive layers II/III and layer V, which are the main sources of callosal neurons in the neocortex (Fame et al., 2011). These results suggest the possibility that the interaction of EphA3 with ephrin-A5 might mediate the repulsive effect between the lateral and medial cortical callosal axons.

We also examined the protein expression pattern of EphA3 by immunohistochemical analysis. We previously reported that almost all EphA3 proteins in cortical neurons are generally transported to their axons (Kudo et al., 2005). Therefore, we only ceptor family proteins (Maruyama et al., 2008). Dissociated cells prepared from the lateral and medial parts of the cortex were treated with ephrin-A5-Fc or control IgG-Fc. The results revealed that the axonal growth of the lateral cortical axons, but not of the medial cortical axons, was inhibited by the treatment of ephrin-A5 (Fig. 4). In addition, a recent in vitro experiment showed that a significant number of cortical axons of E15 rats were stalled on the substrates on which ephrin-A5 was immobilized (Maruyama et al., 2008). These results suggest that ephrin-A5 can induce the repulsive effect on the lateral cortical axons and that this effect is selective for the lateral cortical axons.

\section{EphA3 signaling is required for the segregation of the medial} and lateral cortical axons

To examine whether EphA3 signaling actually mediated the repulsive effect, we next tested the effect of a soluble EphA3 receptor containing the extracellular domain fused to the IgG Fc domain (EphA3-Fc), which would mask the putative EphA3 ligands and thereby inhibit the EphA3-dependent signals (Nishida and Okabe, 2007). Cortical explants were prepared in the same manner as that for the experiment illustrated in Figure 2, and EphA3-Fc or control IgG-Fc (30 $\mu \mathrm{g} / \mathrm{ml}$ each) was added to the culture medium after 1 and $2 \mathrm{~d}$. The results revealed that the medial and lateral cortical axons, which were normally separated from each other in an in vitro culture (separated in 86\%, 6 of 7 samples; Fig. $5 A$ ), were mixed with each other in the presence of EphA3-Fc (separated in 22\%, 2 of 9 samples; Fig. 5B).

To examine the role of EphA3 more specifically, we performed RNA interference (RNAi) experiments in our coculture system, by using vector-based RNAi with shRNAs. To confirm the knockdown efficiency of the constructed shRNA vectors, we examined four shRNA vectors targeting EphA3 and found that two 
of them (EphA3sh\#2 and \#3) markedly decreased the levels of ectopically expressed EphA3 protein in the 293T cells (Fig. 5C). For the subsequent experiments, therefore, mainly the EphA3sh\#2 vector was used. We performed coculture experiments using the medial cortical explants of GFP mice and the lateral cortical explants into which the EphA3sh $\# 2$ vector together with an mCherry expression vector had been transferred by in utero electroporation on E12.5. We found significant admixture of the EphA3knockdown lateral cortical axons with the medial cortical axons compared with the finding in the controls (Fig. 5D-G). These results suggest that the EphA3-expressing lateral cortical axons are repelled by the medial cortical axons through the EphA3 ligand expressed on the medial cortical axons.

\section{"Follower" axon-specific introduction of plasmid vectors by in utero electroporation}

We next sought to address the role of EphA3 in vivo by introducing the EphA3knockdown vector into the lateral cortex by in utero electroporation. It has been shown that CC genesis is triggered at around E15.5 by "pioneer" neurons in the cingulate cortex, which is located in the medial-most part of the cerebral cortex (Lindwall et al., 2007; Piper et al., 2009), and that callosal axons from other regions follow the path of the pioneer neurons (follower axons) (Ozaki and Wahlsten, 1998; Rash and Richards, 2001). We first investigated whether electroporation into the E12.5 lateral cortex could affect the pioneer neurons. To test this, we analyzed how far the E12.5 labeled axons had reached in the E16.0 brain. As the results, we found that at this time point, the GFPpositive axons had not yet passed through the $\mathrm{CC}$, while the $\mathrm{CC}$ had already been formed in part (Fig. 6A,B), suggesting that the pioneer neurons were not affected by this procedure.

Another concern was whether EphA3 knockdown might affect the axonal growth of callosal neurons in general (before contacting the medial cortical axons), since EphA family members have been shown to play roles in axonal growth in other systems. To test this, we investigated axonal growth at an early time-point, before the passage of callosal neurons through the CC. We transfected the EphA3sh\#2 vector with a GFP vector on E12.5 and analyzed the brains on E16.0 to determine how far the growing axons had reached. The results showed that the tip of the growing axons of the EphA3-knockdown neurons reached almost the same point as that in the controls (Fig. $6 C-F$ ), suggesting that EphA3 is not required for growth of callosal axons before contacting the medial cortical axons.
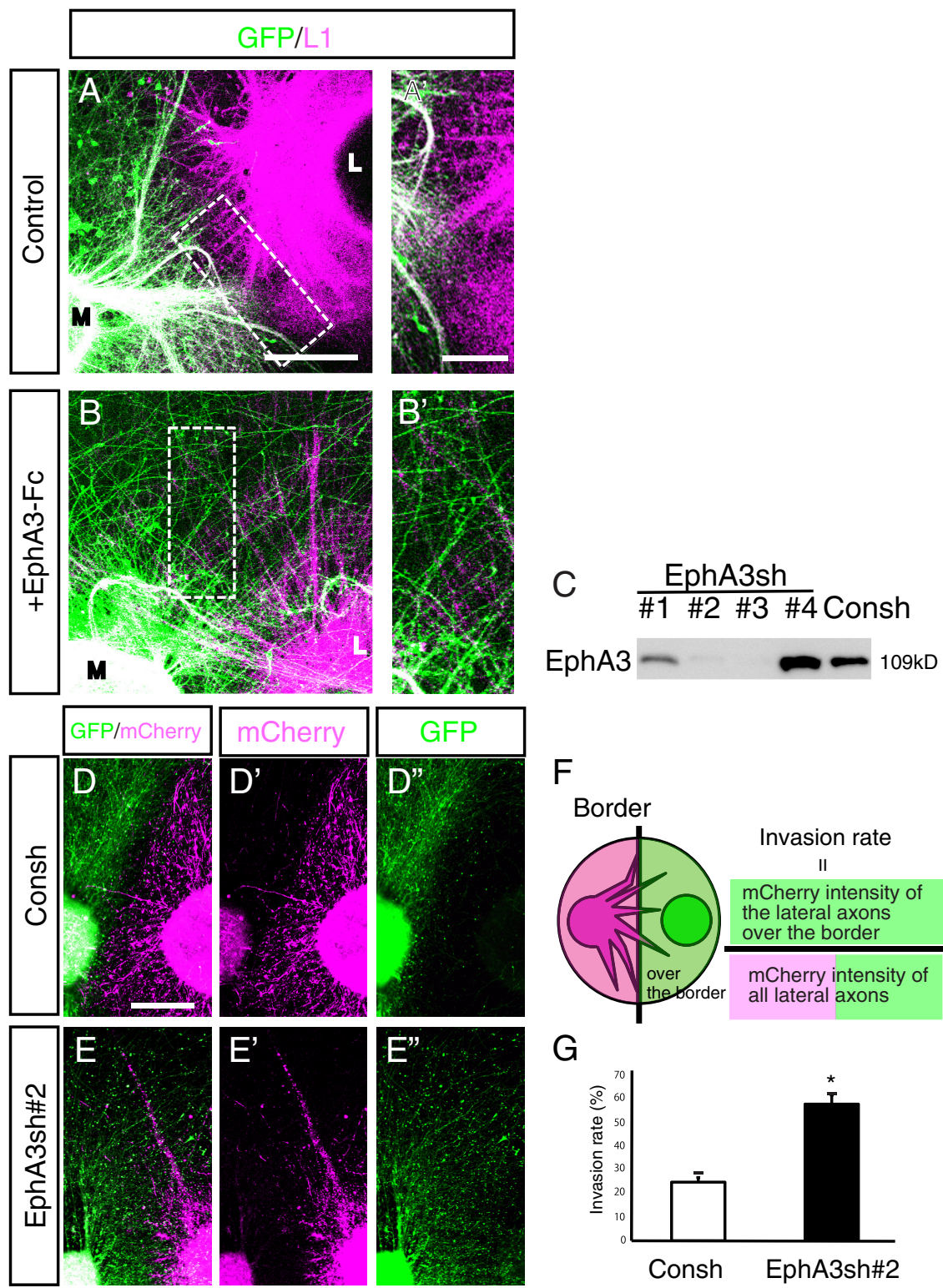

$\mathrm{F}$

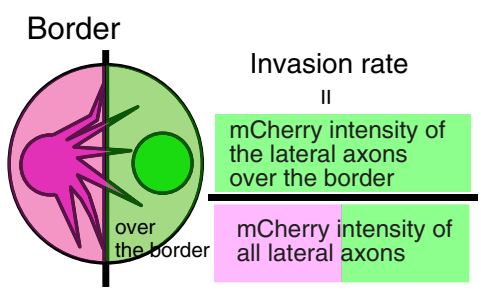

G

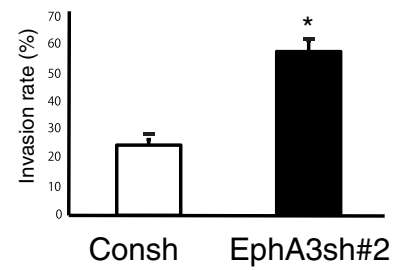

Figure 5. Segregation of the medial and lateral cortical axons is attenuated by EphA3-Fc treatment and EphA3 knockdown in vitro. $A-D$, Cortical explants were prepared as described in Figure 2D.A, $B$, Coculture experiments with EphA3-Fctreatment. $A$, Cocultures of the medial and lateral cortices with added control lgG-Fc proteins. $B$, Cocultures of the medial and lateral cortices with EphA3-Fctreatment. $A^{\prime}$ and $\boldsymbol{B}^{\prime}$ are high-magnification views of the boxed regions in $\boldsymbol{A}$ and $\boldsymbol{B}$, respectively. The medial and lateral cortical axons, which were separated from each other in the in vitro control cultures (separated in $86 \%, 6$ of 7 samples), were mixed with each other in the presence of EphA3-Fc (separated in 22\%, 2 of 9 samples). C, Immunoblotting to examine the efficiency of knockdown by EphA3-silencing vectors on ectopically expressed EphA3. 293T cells were transfected with EphA3sh\#1-\#4 and control shRNA (Consh) vectors together with an EphA3 expression vector and the cell lysates were subjected to immunoblotting for EphA3. EphA3sh\#2 (and also \#3) knocked down EphA3 expression efficiently. $\boldsymbol{D}, \boldsymbol{E}$, Coculture experiments with the EphA3-knockdown lateral and the medial cortical axons. $\boldsymbol{F}$, Schematic representation of the quantification method used in $G$. G, Quantification of the invasion rates of the lateral cortical axons into the medial cortical axons. ${ }^{*} p<0.05$. Scale bars: $A, 100 \mu \mathrm{m} ; \boldsymbol{A}^{\prime}, 50 \mu \mathrm{m} ; \boldsymbol{D}, 200 \mu \mathrm{m}$.

\section{Roles of EphA3 for axon pathfinding of callosal neurons in vivo}

We finally investigated the function of EphA3 during the development of the CC in vivo. We analyzed the axons in the P0.5 lateral cortex that had been electroporated on E12.5. A number of axons from the EphA3-knockdown cells were misrouted around the cingulum, where the growing callosal axons changed direction from horizontal to ventral, and invaded the dorsal part of the CC (Fig. $7 B$, white arrows in $\mathrm{B}^{\prime} ; C$ ), which was not observed in the control experiments (Fig. $7 A, C$ ). A similar phenotype 

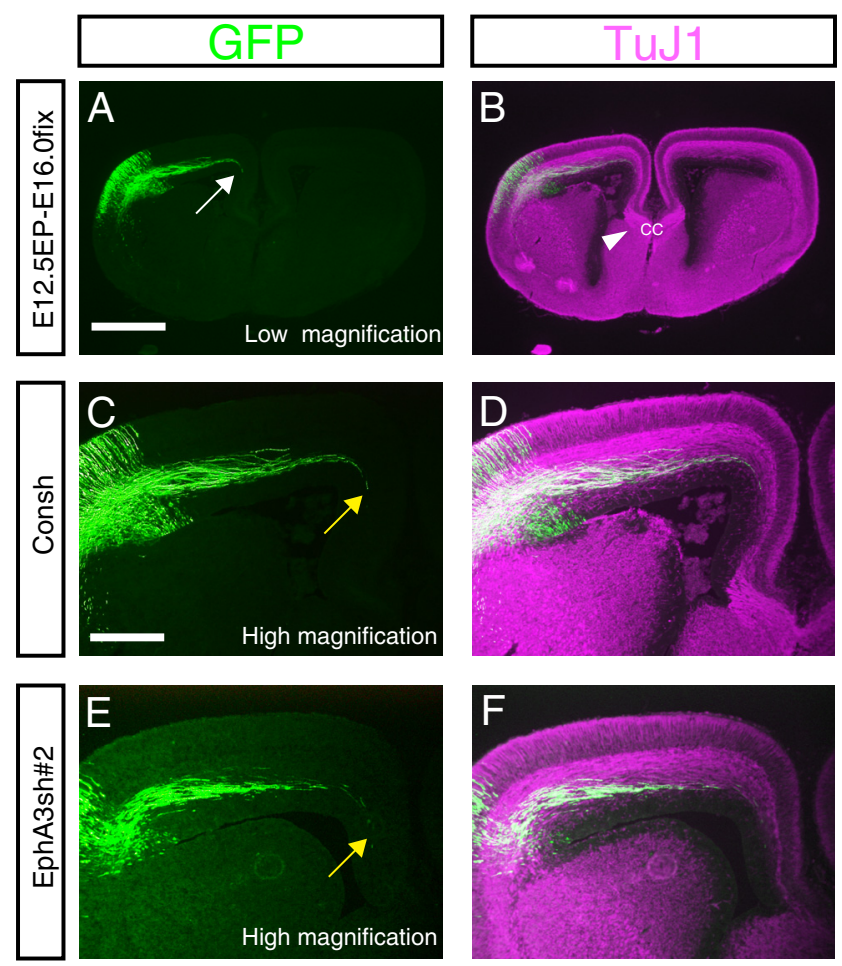

Figure 6. Follower axon-specific introduction of plasmid vectors by in utero electroporation. $\boldsymbol{A}, \boldsymbol{B}$, Immunostaining for GFP $(\boldsymbol{A})$ and TuJ1 $(\boldsymbol{B})$ in the electroporation experiments. We transferred an empty pSilencer 3.0-H1 vector (Consh) together with the GFP vector on E12.5 and fixed the brains on E16.0. At E16.0, the most early follower axons had not yet passed through the CC (arrow in $A$ ), while pioneer axons from the cingulate cortex have already passed (arrowhead in $\boldsymbol{B})$. $\boldsymbol{C}-\boldsymbol{F}$, Consh $(\boldsymbol{C}, \boldsymbol{D})$ or EphA3sh\#2 $(\boldsymbol{E}, \boldsymbol{F})$ was transfected on E12.5, and the brains were fixed on E16.0. The tip of the growing axons of the EphA3-knockdown neurons reached almost the same point compared with that in the controls (yellow arrows in $\boldsymbol{C}, \boldsymbol{E}$ ). Scale bars: $\boldsymbol{A}, 500 \mu \mathrm{m} ; \boldsymbol{C}, 200$ $\mu \mathrm{m}$.

(misrouted axons) was also observed around the midline of the CC (Fig. $7 \mathrm{~J}, \mathrm{~K}$ ). Importantly, these phenotypes were restored by coexpression of an RNAi-resistant EphA3-expressing vector (resEphA3) with EphA3sh\#2 (Fig. 7D-F). These results suggest that EphA3 is required for correct axon pathfinding of the callosal axons from the lateral cortex. Moreover, we found that most axons from the EphA3-knockdown cells became indiscernible immediately after leaving the $\mathrm{CC}$ (white arrowheads in Fig. $7 A, B$; $\mathrm{G}, \mathrm{H}$ ), but reappeared in the rescue experiments (white arrowhead in Fig. 7E; G,I). The defect of axonal growth by EphA3 knockdown was not observed in the E16.0 brain (Fig. 6), in which the electroporated callosal axons had not reached the midline, suggesting that EphA3 signaling stimulates elongation of the callosal axons after the stage when they have crossed the midline.

To further examine the specificity of EphA3 in its role for callosal axon pathfinding, we constructed shRNA vectors targeting EphA5 (EphA5sh) (Fig. 7L), which is widely expressed in the cerebral cortex (Hu et al., 2003), and transferred the EphA5sh vector into the lateral cortex by in utero electroporation in the same manner as describe above. We found that perturbation of EphA5 resulted in neither axonal misrouting in the CC (Fig. 7M), nor elongation failure (Fig. $7 N$ ), suggesting that EphA3 is specifically involved in the development of the CC.

\section{Discussion}

The CC, comprising callosal axons, is the largest structure among commissural connections in eutherian animals. In humans, it consists of $\sim 200$ million axons, making it the largest fiber tract within the CNS (Funnell et al., 2000; Houzel et al., 2002). It integrates information from the right and left hemispheres, and enables numerous complex brain activities (Mihrshahi, 2006). The complex mechanisms underlying CC development have been reported by many studies (Lindwall et al., 2007), but have not been solved completely.

Interactions between the callosal axons and midline glial structures have been suggested to play critical roles in callosal axon guidance (Shu and Richards, 2001; Bush and Soriano, 2009). In addition, previous studies have indicated important roles of fasciculation and segregation of axons in the development of neural circuits in other systems (Horton and Levitt, 1988; Faulkner et al., 2008). However, it has remained unclear whether such a mechanism involving axon-axon interactions, another major mechanism for axon pathfinding, might be involved in CC development.

In the present study, we found that the repulsive interactions between callosal axons originating from the medial and lateral cerebral cortices, which were best demonstrated by the axonal segregation observed in the in vitro culture experiments. These repulsive interactions were further supported by observations in vivo, that (1) the axons from the medial and lateral cortices passed through distinct regions (dorsal and ventral parts of the CC, respectively) and that (2) the segregation was attenuated by inhibition of EphA3, a receptor mediating the repulsive signaling. These results suggest that repulsive axon-axon interactions play an important role in the development of the CC.

The Eph family of receptor tyrosine kinases and their membrane-anchored ephrin ligands are known to play central roles in axon guidance in a wide variety of systems (Huot, 2004; Sakano, 2010). Members of the EphB and ephrin-B family have been demonstrated to play critical roles in callosal axon guidance (Mendes et al., 2006; Bush and Soriano, 2009). Single or double mutants of genes of this family often show marked agenesis of the CC (Mendes et al., 2006). On the other hand, although several members of the EphA family are expressed in the cortical layers, in which many neurons send axons to the contralateral cortex through the CC (Yun et al., 2003), only a few studies have clarified the role of the EphA family; overexpression of a kinasenegative EphA5 resulted in partial agenesis of the CC (Hu et al., 2003). What then is the difference in roles between the EphA and $\mathrm{B}$ families? We speculate that these families function at different steps of CC development. It has been shown that CC genesis is triggered by pioneer neurons in the cingulate cortex (Lindwall et al., 2007; Piper et al., 2009). Pioneer axons first form the path of commissural neurons through interactions with the midline glial structures, and callosal axons from other regions follow those of the pioneer neurons (Ozaki and Wahlsten, 1998; Rash and Richards, 2001). Given that knock-out of members of the EphB family often resulted in a complete loss of the CC (Mendes et al., 2006), it is possible that EphB is primarily involved in an early process of $\mathrm{CC}$ development, such as the regulation of pioneer neurons; the pioneer axons expressing EphB and/or ephrin-B family members might be guided by the midline glial structures. In this study, we found EphA3-mediated axonal interactions in follower axons, suggesting the possibility that the EphA family might contribute more to the later phase of development of the CC than to the early processes, which is consistent with relatively mild phenotypes observed in the CC in mutant mice of this family (Hu et al., 2003).

EphA3 expressed in the lateral cortical axons is thought to receive signals from yet-to-be determined ligands expressed in the medial cortical axons. We found that ephrin-A5 mRNA is 

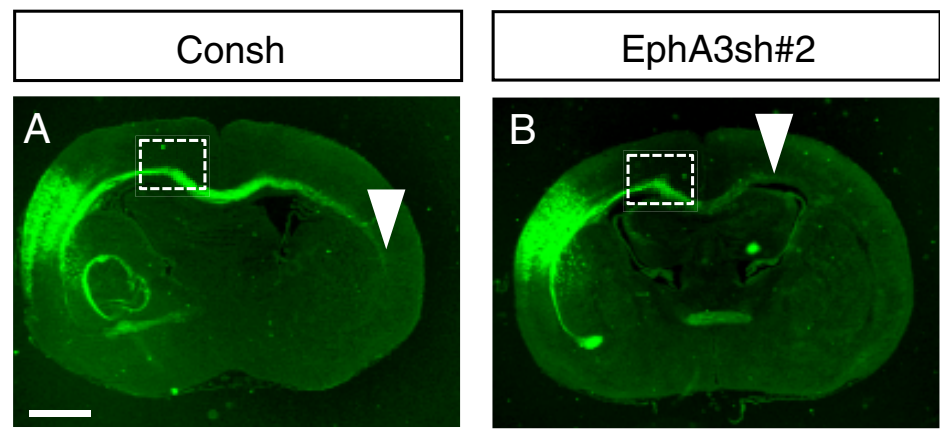

\section{EphA3sh\#2 + resEphA3}
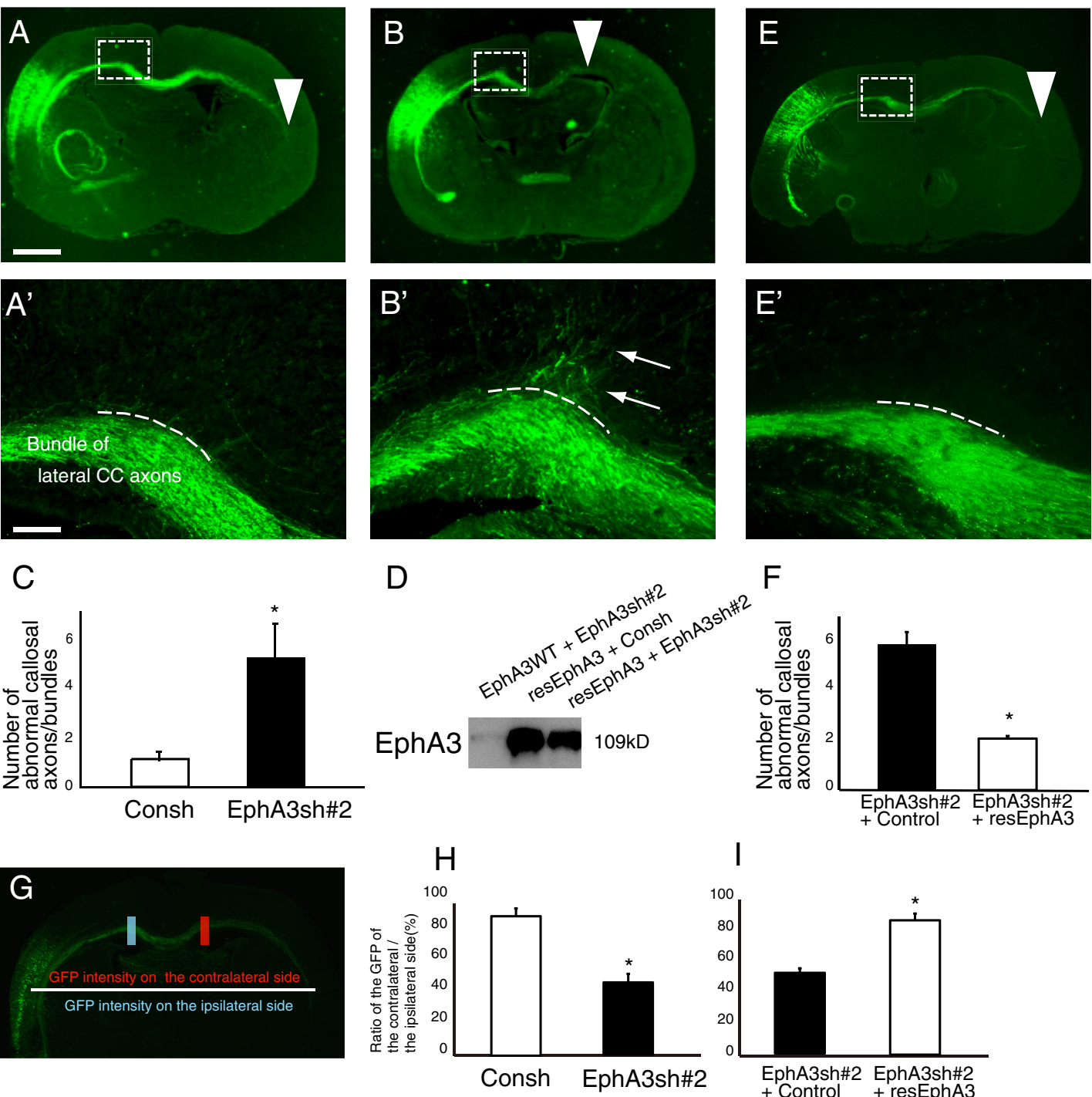

\section{$\mathrm{F}$}
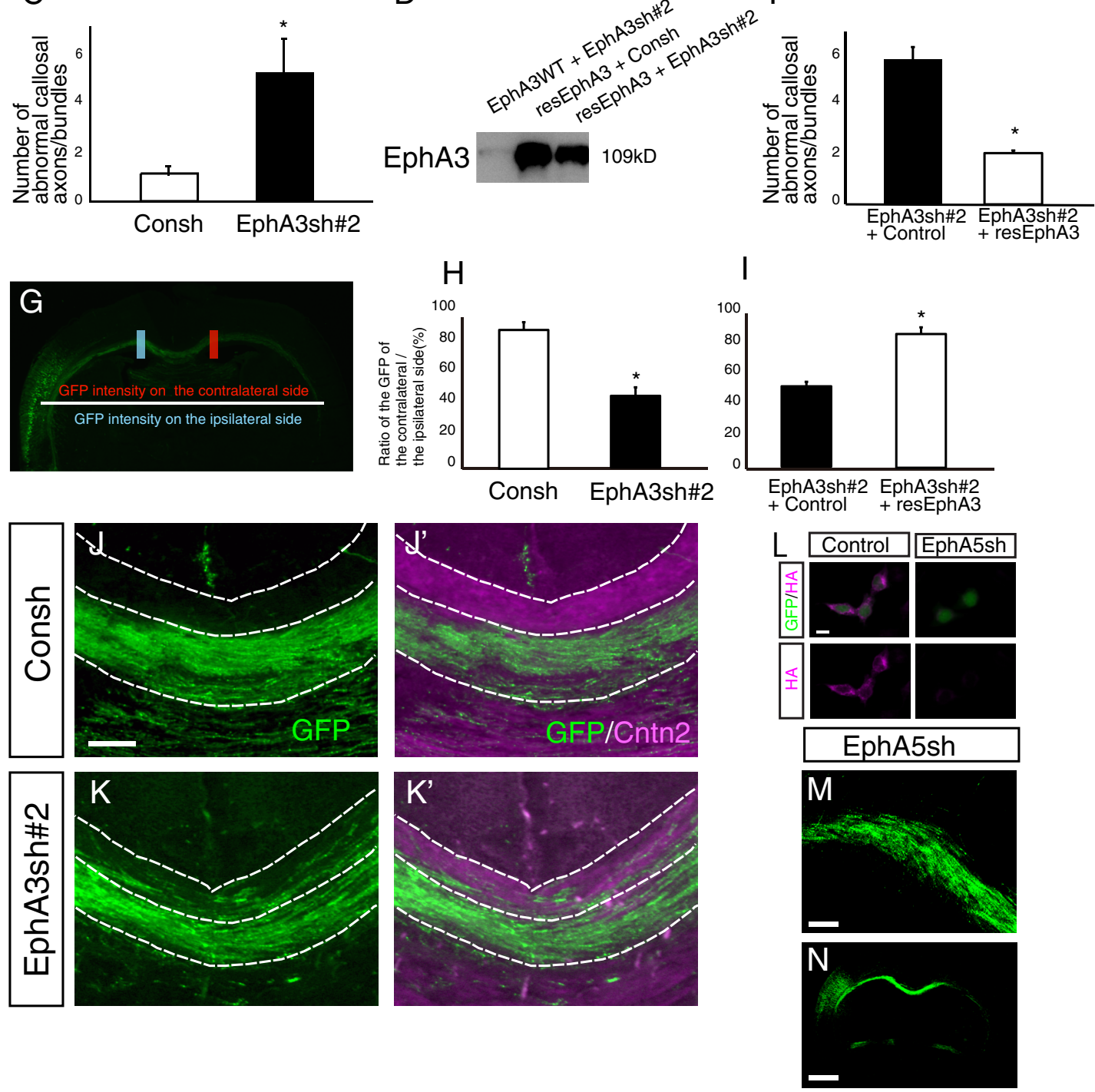

Figure 7. EphA3 signaling is required for proper pathfinding of the callosal axons derived from the lateral cortex. $A, B, E$, Immunostaining for GFP in RNAi experiments for EphA3 $(\boldsymbol{A}, \boldsymbol{B})$ and the rescue experiments $(\boldsymbol{E}) \cdot \boldsymbol{A}^{\prime}, \boldsymbol{B}^{\prime}$, and $\boldsymbol{E}^{\prime}$ are high-magnification images of the boxed regions in $\boldsymbol{A}, \boldsymbol{B}$, and $\boldsymbol{E}$. Abnormal axons/bundles are indicated with white arrows in $\boldsymbol{B}^{\prime}$. The length of the longest axon was also decreased by EphA3-knockdown (white arrowheads in $\boldsymbol{A}$ and $\boldsymbol{B}$ ). $\boldsymbol{C}$, The number of abnormal axons/bundles in $\boldsymbol{A}^{\prime}$ and $\boldsymbol{B}^{\prime}$. We analyzed 23 brains (Consh, 11; (Figure legend continues.) 


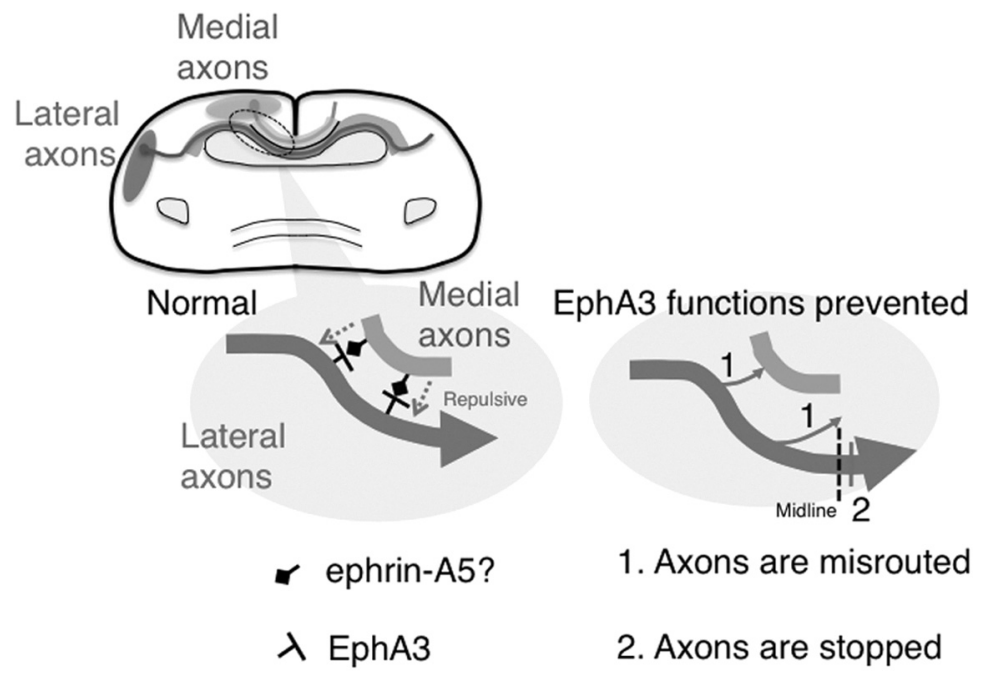

Figure 8. Model of interaction between the medial and lateral callosal axons. The repulsive effects between the medial and lateral cortical axons contribute to the axonal segregation in the CC. Under normal conditions, lateral cortical axons would use the interaction with medial cortical axons to project to the contralateral neurons in the lateral cortex through the $\mathrm{CC}$. When the functions of EphA3 are inhibited, the lateral cortical axons cannot interact with the medial cortical axons, disrupting their correct pathfinding and/or proper extension.

expressed in the medial region of the cerebral cortex, complementary to EphA3 mRNA, and that ephrin-A5 can selectively inhibit the growth of the lateral cortical axons in an in vitro culture, suggesting the possibility of ephrin-A5 as an endogenous ligand for EphA3 (Himanen et al., 2004) on the lateral cortical axons. However, the result that ephrin-A5 mRNA is not expressed in the medial-most cortex (the cingulate/retrosplenial cortex) suggests that other ligand molecules are also involved in this event. We assume that the lateral cortical axons in vivo could run freely within a bundle of axons of the same kind, but when they encounter the medial cortical axons at the boundary, they might be repelled and follow the path of axons of the same kind. Such interactions appear to occur in regions where axons change direction, because misrouted axons by EphA3 knockdown were often observed in such regions.

Our results also demonstrated that EphA3 knockdown decreased the number of axons in the cortex contralateral to the electroporated side, suggesting that EphA 3 is required for axonal elongation around

$\leftarrow$

(Figure legend continued.) EphA3sh\#2, 12).D, Immunoblotting to examine the efficiency of rescue by resEphA3 for EphA3sh\#2.293T cells were transfected with the indicated plasmids, and the cell lysates were subjected to immunoblotting for EphA3. The resEphA3 plasmid appeared to be resistant to knockdown by EphA3sh\#2. $\boldsymbol{E}$, The elongation failure of callosal axons was rescued by cotransfection with the rescue vector (arrowhead in $\boldsymbol{E}$ ). $\boldsymbol{F}$, The number of abnormal axons/bundles in the rescue experiments. We analyzed 21 brains (EphA3sh\#2+Control, 13; EphA3sh\#2+resEphA3, 8). $\mathbf{G}$, Schematic representation of the quantification method used in $\boldsymbol{H}$ and $I . H, I$, Quantitative data of the ratio of the intensity of GFP-positive axons leaving the $\mathrm{CC}$ to that of the GFP-positive axons entering the $C(\mathrm{in}$ the knockdown experiments $(\boldsymbol{H})$ and the rescue experiments $(\boldsymbol{I}) . \boldsymbol{J}, \boldsymbol{K}$, Abnormal axons observed around the midline of the CC. The GFP-positive axons around the midline from the control $(\boldsymbol{J})$ and EphA3-knockdown $(\boldsymbol{K})$ experiments are shown. $\boldsymbol{J}^{\prime}$ and $\boldsymbol{K}^{\prime}$ show merged images of the GFP signals with immunostaining for Cntn2 (magenta). While most of the lateral cortical axons passed through the ventral part of the $\mathrm{CC}^{\mathrm{C}}$ in the control, the EphA3-knockdown lateral cortical axons could not follow the normal axonal trajectory. L, Immunocytochemistry for HA to examine the efficiency of knockdown by EphA5silencing vectors on ectopically expressed HA-EphA5. EphA5sh effectively knocked down the expression of EphA5. $\boldsymbol{M}, \boldsymbol{N}$, Immunostaining for GFP in RNAi experiment for EphA5. $\boldsymbol{M}$, Normal axon pathfinding observed around the midline of the $C($ in the EphA5-knockdown neurons. $\boldsymbol{N}$, Normal axonal elongation was also observed. ${ }^{*} p<0.05$. Scale bars: $A, N, 500 \mu \mathrm{m} ; A^{\prime}, J, M, 100$ $\mu \mathrm{m} ; L, 10 \mu \mathrm{m}$. and after the stage of midline crossing. There are at least two possibilities to explain this elongation failure. One is that the axonal defasciculation by EphA3 knockdown may result in failure of correct axon pathfinding, as observed in other systems (Horton and Levitt, 1988; Faulkner et al., 2008); the restricted narrow path by the repulsive signal from the medial cortical axons in the CC may support elongation of the lateral cortical axons (Fig. 8). Another possibility is that EphA3 signaling is involved in the repulsion of the growth cones from the midline, as callosal axons change the relationship with the midline from attractive to repulsive interactions during midline crossing.

Many studies using knock-out and transgenic mice have reported agenesis of the CC (Richards et al., 2004). However, as the formation of the CC is controlled by a number of factors, including pioneer neurons, environments such as the midline glial structures, and axonal growth of follower neurons, analyses of these mutant mice were not necessarily sufficient for describing the primary causes. Our system using in utero electroporation (Tabata and Nakajima, 2001), which enabled us to focus on the axonal development of follower, not pioneer axons, would be a powerful tool for analyzing CC development.

Axon regulation at the cohort level, such as axon fasciculation and segregation, has been shown to play important roles in axon pathfinding (Gallarda et al., 2008). The presented data are the first evidences of the involvement of EphA-ephrin-A signaling in the segregation of axonal cohorts that originate from different topographic origins. Axonal segregation at a cohort level through semaphorin-neuropilin interactions has recently been reported in the pathfinding of olfactory neurons, in which the topography of the neurons in the olfactory epithelium is transferred to their target, the olfactory bulb (Imai et al., 2009; Sakano, 2010). Such preordered segregation was also observed in the visual system (Chan and Chung, 1999; Plas et al., 2005). Although we could not investigate the final targeting of the callosal axons in the absence of EphA3 because of the failure of axon elongation, preordered segregation through axon-axon interactions could be one of the basic mechanisms for the axon pathfinding with retained topography in different organizations, which presumably contributes to ensure precise axonal targeting. It would be of great interest to investigate axon-axon interactions and the underlying molecular mechanisms in other topographic projection systems.

\section{References}

Bush JO, Soriano P (2009) Ephrin-B1 regulates axon guidance by reverse signaling through a PDZ-dependent mechanism. Genes Dev 23:1586-1599.

Chan SO, Chung KY (1999) Changes in axon arrangement in the retinofugal [correction of retinofungal] pathway of mouse embryos: confocal microscopy study using single- and double-dye label. J Comp Neurol 406:251-262.

Dufour A, Seibt J, Passante L, Depaepe V, Ciossek T, Frisén J, Kullander K, Flanagan JG, Polleux F, Vanderhaeghen P (2003) Area specificity and topography of thalamocortical projections are controlled by ephrin/Eph genes. Neuron 39:453-465.

Egea J, Klein R (2007) Bidirectional Eph-ephrin signaling during axon guidance. Trends Cell Biol 17:230-238. 
Fame RM, MacDonald JL, Macklis JD (2011) Development, specification, and diversity of callosal projection neurons. Trends Neurosci 34:41-50.

Faulkner RL, Low LK, Liu XB, Coble J, Jones EG, Cheng HJ (2008) Dorsal turning of motor corticospinal axons at the pyramidal decussation requires plexin signaling. Neural Dev 3:21.

Funnell MG, Corballis PM, Gazzaniga MS (2000) Cortical and subcortical interhemispheric interactions following partial and complete callosotomy. Arch Neurol 57:185-189.

Gallarda BW, Bonanomi D, Müller D, Brown A, Alaynick WA, Andrews SE, Lemke G, Pfaff SL, Marquardt T (2008) Segregation of axial motor and sensory pathways via heterotypic trans-axonal signaling. Science 320:233-236.

Himanen JP, Chumley MJ, Lackmann M, Li C, Barton WA, Jeffrey PD, Vearing C, Geleick D, Feldheim DA, Boyd AW, Henkemeyer M, Nikolov DB (2004) Repelling class discrimination: ephrin-A5 binds to and activates EphB2 receptor signaling. Nat Neurosci 7:501-509.

Horton HL, Levitt P (1988) A unique membrane protein is expressed on early developing limbic system axons and cortical targets. J Neurosci 8:4653-4661.

Houzel JC, Carvalho ML, Lent R (2002) Interhemispheric connections between primary visual areas: beyond the midline rule. Braz J Med Biol Res 35:1441-1453.

Hu Z, Yue X, Shi G, Yue Y, Crockett DP, Blair-Flynn J, Reuhl K, Tessarollo L, Zhou R (2003) Corpus callosum deficiency in transgenic mice expressing a truncated ephrin-A receptor. J Neurosci 23:10963-10970.

Huot J (2004) Ephrin signaling in axon guidance. Prog Neuropsychopharmacol Biol Psychiatry 28:813-818.

Ikawa M, Yamada S, Nakanishi T, Okabe M (1998) 'Green mice' and their potential usage in biological research. FEBS Lett 430:83-87.

Imai T, Yamazaki T, Kobayakawa R, Kobayakawa K, Abe T, Suzuki M, Sakano H (2009) Pre-target axon sorting establishes the neural map topography. Science 325:585-590.

Kaneko M, Nighorn A (2003) Interaxonal Eph-ephrin signaling may mediate sorting of olfactory sensory axons in Manduca sexta. J Neurosci 23:11523-11538.

Kaprielian Z, Runko E, Imondi R (2001) Axon guidance at the midline choice point. Dev Dyn 221:154-181.

Kawai J, Shinagawa A, Shibata K, Yoshino M, Itoh M, Ishii Y, Arakawa T, Hara A, Fukunishi Y, Konno H, Adachi J, Fukuda S, Aizawa K, Izawa M, Nishi K, Kiyosawa H, Kondo S, Yamanaka I, Saito T, Okazaki Y, et al. (2001) Functional annotation of a full-length mouse cDNA collection. Nature 409:685-690.

Kudo C, Ajioka I, Hirata Y, Nakajima K (2005) Expression profiles of EphA3 at both the RNA and protein level in the developing mammalian forebrain. J Comp Neurol 487:255-269.

Lemke G, Reber M (2005) Retinotectal mapping: new insights from molecular genetics. Annu Rev Cell Dev Biol 21:551-580.

Lindwall C, Fothergill T, Richards LJ (2007) Commissure formation in the mammalian forebrain. Curr Opin Neurobiol 17:3-14.

Martínez A, Soriano E (2005) Functions of ephrin/Eph interactions in the development of the nervous system: emphasis on the hippocampal system. Brain Res Brain Res Rev 49:211-226.

Maruyama T, Matsuura M, Suzuki K, Yamamoto N (2008) Cooperative activity of multiple upper layer proteins for thalamocortical axon growth. Dev Neurobiol 68:317-331.

Matsunami K, Kawashima T, Ueki S, Fujita M, Konishi T (1994) Topography of commissural fibers in the corpus callosum of the cat: a study using WGA-HRP method. Neurosci Res 20:137-148.

Mendes SW, Henkemeyer M, Liebl DJ (2006) Multiple Eph receptors and B-class ephrins regulate midline crossing of corpus callosum fibers in the developing mouse forebrain. J Neurosci 26:882-892.
Mihrshahi R (2006) The corpus callosum as an evolutionary innovation. J Exp Zool B Mol Dev Evol 306:8-17.

Miller K, Kolk SM, Donoghue MJ (2006) EphA7-ephrin-A5 signaling in mouse somatosensory cortex: developmental restriction of molecular domains and postnatal maintenance of functional compartments. J Comp Neurol 496:627-642.

Mitchell BD, Macklis JD (2005) Large-scale maintenance of dual projections by callosal and frontal cortical projection neurons in adult mice. J Comp Neurol 482:17-32.

Mizuno H, Hirano T, Tagawa Y (2010) Pre-synaptic and postsynaptic neuronal activity supports the axon development of callosal projection neurons during different postnatal periods in the mouse cerebral cortex. Eur J Neurosci 31:410-424.

Niquille M, Garel S, Mann F, Hornung JP, Otsmane B, Chevalley S, Parras C, Guillemot F, Gaspar P, Yanagawa Y, Lebrand C (2009) Transient neuronal populations are required to guide callosal axons: a role for semaphorin 3C. PLoS Biol 7:e1000230.

Nishida H, Okabe S (2007) Direct astrocytic contacts regulate local maturation of dendritic spines. J Neurosci 27:331-340.

Okazaki Y, Furuno M, Kasukawa T, Adachi J, Bono H, Kondo S, Nikaido I, Osato N, Saito R, Suzuki H, Yamanaka I, Kiyosawa H, Yagi K, Tomaru Y, Hasegawa Y, Nogami A, Schönbach C, Gojobori T, Baldarelli R, Hill DP, et al. (2002) Analysis of the mouse transcriptome based on functional annotation of 60,770 full-length cDNAs. Nature 420:563-573.

Ozaki HS, Wahlsten D (1998) Timing and origin of the first cortical axons to project through the corpus callosum and the subsequent emergence of callosal projection cells in mouse. J Comp Neurol 400:197-206.

Piper M, Plachez C, Zalucki O, Fothergill T, Goudreau G, Erzurumlu R, Gu C, Richards LJ (2009) Neuropilin 1-Sema signaling regulates crossing of cingulate pioneering axons during development of the corpus callosum. Cereb Cortex 19 [Suppl 1]:i11-i21.

Plachez C, Richards LJ (2005) Mechanisms of axon guidance in the developing nervous system. Curr Top Dev Biol 69:267-346.

Plas DT, Lopez JE, Crair MC (2005) Pretarget sorting of retinocollicular axons in the mouse. J Comp Neurol 491:305-319.

Rash BG, Richards LJ (2001) A role for cingulate pioneering axons in the development of the corpus callosum. J Comp Neurol 434:147-157.

Richards LJ, Plachez C, Ren T (2004) Mechanisms regulating the development of the corpus callosum and its agenesis in mouse and human. Clin Genet 66:276-289.

Sakano H (2010) Neural map formation in the mouse olfactory system. Neuron 67:530-542.

Shu T, Richards LJ (2001) Cortical axon guidance by the glial wedge during the development of the corpus callosum. J Neurosci 21:2749-2758.

Tabata H, Nakajima K (2001) Efficient in utero gene transfer system to the developing mouse brain using electroporation: visualization of neuronal migration in the developing cortex. Neuroscience 103:865-872.

Tachikawa K, Sasaki S, Maeda T, Nakajima K (2008) Identification of molecules preferentially expressed beneath the marginal zone in the developing cerebral cortex. Neurosci Res 60:135-146.

Tole S, Gutin G, Bhatnagar L, Remedios R, Hébert JM (2006) Development of midline cell types and commissural axon tracts requires Fgfrl in the cerebrum. Dev Biol 289:141-151.

Vanderhaeghen P, Lu Q, Prakash N, Frisén J, Walsh CA, Frostig RD, Flanagan JG (2000) A mapping label required for normal scale of body representation in the cortex. Nat Neurosci 3:358-365.

Yun ME, Johnson RR, Antic A, Donoghue MJ (2003) EphA family gene expression in the developing mouse neocortex: regional patterns reveal intrinsic programs and extrinsic influence. J Comp Neurol 456:203-216. 